\title{
The Green Design Idea and Practice Research of the Apartment for the Aged based on Environmental Protection
}

\author{
Xiangwei WU \\ Hengshui University \\ Hengshui,Hebei, China
}

\begin{abstract}
The so-called aging problem is the inevitable result of social progress. China has entered the aging society in the last century. In recent years, the family structure of China has become increasingly miniaturized. People's viewpoints on public pension has also been changed. The apartment for the aged gets more and more popular with old people. The old people also pay more attention to whether the living environment of the apartment for the aged will meet their physiological and psychological needs. This paper explores the key points about the design of the apartment for the aged from the several aspects, such as the selection and planning of the construction site, the design of green public space, the application of solar energy technology, the intelligent technology, the operation management of the apartment for the aged and so on. This paper analyzes the types of environmental resources and the design methods which have their own characteristics.And this paper combines the project of the apartment for the aged in Luquan city of Shijiazhuang and practices the green design method of the elderly community and the apartment for the aged based on environmental resources.
\end{abstract}

Keywords- Environmental Resources, the Elderly Community, the Apartment for the Aged

\section{INTRODUCTION}

Currently, our country is going through the transitional period. With the rapid improvement of the economic level and the implementation of the family planning policy, the traditional family structure has greatly changed. The urban family structure increasingly presents $4: 2: 1$ pattern, that is to say, the family size gets small and the burden for the old people's children increases. And if the couple, two persons, at the same time work in another city, it will lead to the 4 old people in the state of "empty nest". The problem of supporting old people will make us worry. While on the other hand, many old people's pension ideas have changed. The traditional idea of "Bring up their children for old age" has been out of date. And the old people are not willing to bring their children too much burden and they want to have their own independent space and life. Therefore, the traditional mode of the aged-care at home can't meet the needs of old people. And the pension model-the apartment for the aged which can provide all the things of the housing, the services and health care for the old people will become an excellent choice to solve the problem of supporting old people and promote harmonious development of the society.
Green building refers to the kind of building can provide healthy, comfortable and safe space of dwelling, working and living, and be able to save resources, protect environment in the construction of the entire life cycle (from the material production, the planning and design, the construction, and the maintenance and the demolition in operation process). At present the globalization is faced with climate warming, air pollution and the shortage of resources. Promoting green building heavily can reduce the load on the environment. This complies with the implementation of friendly environmental strategy. And this can achieve harmonious coexistence and sustainable development among people, buildings and environment.

\section{THE TYPES OF ENVIRONMENTAL RESOURCE AND PlanNING CHALlENGES WHICH ARE SUITED FOR THE ELDERLY COMMUNITY}

\section{A. Forest Resources}

There are a large area of woodland in the suburbs of many cities. These woodlands form a natural oxygen bar which are very suitable for the old people to have long-term or short-term life andculture. However, how to not destroy the forest resources in the planning construction and architectural design, how to improve the forest fire prevention system and make the appropriate planning layout and architectural design are a big challenge for planning.

Water-body resources include streams, reservoirs, mountain streams, ponds and so on. The water-body can form excellent natural landscape. And it has the very good landscape therapeutic effect on some diseases, and it is also the indispensable and important resources for the garden construction of rehabilitation.

When we make use of the water-body resources, we need to take the influence of flood control and other natural disasters into consideration. We need to set up safety protective measures. Combining with the buildings, we should design different spaces for activities, such as the design of water loving, beinng close to water, playing with water, watching the water an so on. And we should make use of water-body resources flexibly.

\section{B. Landscape Resources}

Landscape resources mainly refers to mountain resources, valley resources and so on in the suburbs of the cities. As far as mountain resources are concerned, they provide a unique living environment, but the biggest design challenge is how to solve the difference of the ground elevation, how 
to make reasonable barrier-free design and provide convenient transportation services and medical services for the old people. Valley resources are often combined with mountain resources. As far as the valley resources which still bear the flood discharge function are concerned, they are more suitable for the construction of valley landscape, but they are not suitable for the construction of building facilities.

\section{The BuILdING Design STRATEGIES OF THE ELDERLY COMMUNITY WITH THE TYPE OF ENVIRONMENTAL RESOURCES}

Internationally, the construction of the centralized community for old people has a long history. In the United States, people, whether retired or not, over 55 years old, can adopt the mode of buying or renting to live in the elderly community. When people adopt the mode of buying, they usually get the apartments which are shared with others and villatic residences. When people adopt the mode of renting, they usually get the apartments for the old people with service facilities. According to the activity ability of the old people, the residences can be also divided into the residences of self-care type, the residences of assistant type and the residences of nursing type. The design of the apartment for the aged has obviously changed over the past more than 20 years. There has been growing recognition that the awareness of the needs for the old people, social care, personalized nursing, the care and intervention from friends and family and beautiful natural rehabilitation environment can protect the needs of healthy life for the old people better. As far as the residences of the old people which have the advantage of environment resources are concerned, the core is to solve the old people's requirements of living, rehabilitation and medical treatment better by the help of environment resources.

First of all, people can combine with the site conditions to do the adaptability analysis of using the land and the analysis of land value. Because the site conditions of land parcels with the type of environmental resources are all more complex, people can analyze the difference of elevation and height of the sites, slope and aspect, run-off and son on with the help of GIS and other softwares. Generally speaking, the old people's residences of self-care type require lower levels of the sites. They can have much more pursuit of privacy and site characteristics. But the residences of assistant type and the residences of nursing type require higher levels of the sites. They should be as close as possible to the site entrance. And the locations of them should be selected relatively flat terrain for their layout.

In order to reduce the influence of building facilities for natural resources, people can odopt the layout mode of residential groups. And according to the level of public service facilities, people can provide the fittingfacilities flexibly in residential groups, residential area and residential district. And people can connect various groups with safe and flexible slow traffic system and can provide various and vigorous training places for the old people. And these will be their important public intercourse space.
IV. THE GREEN COMMUNITY FOR THE AGED AND THE

DESIGN CASE OF APARTMENTS FOR THE AGED BASED ON THE ADVANTAGES OF ENVIRONMENTAL RESOURCES

\section{A. Project Background}

This project is located in Luquan city of Shijiazhuang in Hebei province. It adjoins Shijiazhuang. The project includes the river valley land and the valley land. It is typical land for the elderly community in suburb with the advantage of environmental resources.

The design site has a total of 86.6 hectares. There is a large rugged terrain in the internal site. A valley from east to west sequences the valley lands which are scattered in the valleys between the north and the south mountain. There is very poor traffic conditions in the internal site. However, there is good vegetation condition.

\section{B. Site Analysis}

In view of the natural factors and human factors, the internal site forms lots of areas with dramatic changes, including steep slopes and cliffs. These sites bring difficulty for this planning, but they also form the conditions which create a low-density residential area and characteristic landscape. People use GIS software to analyze the site. The height difference between the entrance to the valley located in the west side of the site and the valley in the east is nearly 200 meters. The terrain of the main valley area is relatively smooth, and the terrain of the intersection area between the valley and the mountain has big changes. All these things bring the difficulty for the planning and design. At the same time, people also analyze the slope and aspect of the site and mark off the level and scope of construction land.

By the analysis above, people make the scoring and the grading for every block of the site from the four aspects, such as light, traffic, landscape, confidentiality and so on. And people plan the area of river valley which is in the middle of the site and has very strong publicness as ecological corridor. While people design the area of southern slope which has good natural lighting and landscape as the elderly community with CCRC full care. While people design the area of northern slope which has poor natural lighting but has good resources of forest vegetation as the destination, the elderly community for holiday. All these above take the differnt requirements of supporting the old peole with all-weather and intermittent mode.

\section{Planning Concept}

The design site is located in the valley. A long vale connects the valleys dispersed in high mountains and lofty hills. It seems to be chaotic. But each piece of land is hidden in the mountain forest. It is quiet, beautiful and natural with the artistic conception of "going back to rural residence". Long and narrow vale seems to be like the flying phoenix. And each piece of land scattered in the mountains seems to be like the colorful feathers of the phoenix. Since ancient times, the Phoenix has represented the good symbol of good luck and conjugal bliss in Chinese culture. This scheme adopts " the colorful phoenix is coming 
and the mountain forest offers auspiciousnes" as the concept of planning and design. And it combines with the site topography and the planning design to analyze the planning layout and the design intention of landscape. It tries to create the unique the elderly community with scenery which takes the natural ecological landscape as the core resources.

\section{Planning Structure and Function Division}

The planning structure is an area, a core zone and six districts. The area is an ecological corridor. The creation of it concentratedly embodies the advantages of environmental resources in this area. The core zone is the core of public service which arranges the comprehensive hospital, the recreational facilities for the old people, supermarkets and the shopping districts for the old people. Three groups are the three groups in the comprehensive community for the old people, respectively including the residences of self-care type, the residences of assistant type and the residences of nursing type, the three residences mentioned above.

The whole site can be divided into 6 functional divisions, which are respectively the cohesive division of landscape, the demonstration division, the rehabilitation health division, the holiday division for supporting the old people, the comprehensive community for the old people and the division of public service.

\section{E. Slow Traffic System}

People combine with the natural landscape and design various forms of pedestrian road system, namely the slow roads with scenery. When people enter there from the independent entrance, they enter the narrow pedestrian road at once to create a quiet atmosphere. After people arrive in the first landscape node, they begin to enter the pedestrian road in the sky. And the broad line of sight is suddenly opened.This pedestrian road solves the problems of the connection of each group and the site elevation difference well. And people can smoothly enter the public service area. Then, people can come to the waterfront pedestrian road with beautiful landscape and fresh air. Perfect pedestrian road and open space are connected together. This not only provides the best fitness method but also provides the sites of social intercourse for the old people.

\section{F. The Guideline of Architectural Design}

People combine with the site conditions and take the group as the unit to arrange the residences for the old people. The buildings in the group are connected with the long corridor which can withstand wind and rain around the site with core activities. The north-south building is a residential building which is connected with the internal corridor with the orientation of north. People arrange public activity spaces in the long corridor which can withstand wind and rain with the connection of each building, including the underlying medical service spot, small supermarket, the property management office and so on. People also arrange the nurse station in each layer, public living room, public dining room, activity room and so on to meet the social intercourse of the old people.

And this kind of architectural form which takes groups as a big unit can also be combined flexibly according to the terrain of site. Each product can take traffic as the core. And it gives attention to the flexible reverse of both the orientation and the landscape.

When people make the architectural design, they need to pay attention to the barrier-free design and the health care facilities which are desined according to the physical condition of the old people, such as the antiskid processing of the floor, the design of continuous eaves, the rest chairs, the mailboxs and message boards and so on.

people arrange the public service facilities with three levels in the buildings. people take the core area throughout the region as the main area to build the service system with the first level, including the comprehensive hospital, supermarkets and the shopping districts for the old people. And the public service facilities with second level are arranged in the entrance or at the center of the group, including the medical service spot and small convenience stores, etc. And the public service facilities with third level are arranged in the the inside of each unit with the first layer, including the nursing stations, the small restaurants, the audio-visual rooms etc.

\section{CONCLUSIONS}

The cases above have practiced the elderly community based on environmental resources and the architectural design method of the apartment for the aged. They have opened up a path which is both natural, healthy, comfortable and convenient for the the residential mode of supporting the old people.

\section{ACKNOWLEDGEMENT}

Hebei province "The Twelfth Five Year Plan " planning project(13110006).

\section{References}

[1] Hu Xuelian. Research on the Design of Living Environment for the Apartments for the Aged in Nanjing City[D]. Nanjing Forestry University, 2013.

[2] Ma Zheming. The Study of Humanized Design for the Apartments for the Aged [D]. Hebei University of Engineering, 2013.

[3] Tao Xi. Moving towards "Humanity Care" from the"Indifferent and Neglect" ----The Effectiveness Research on the Design of Road Space for the Apartments for the Aged [D]. Jiangxi Normal University, 2013.

[4] Fan Xintao. The Study of Architectural Design for the Apartments for the Aged [D]. Xi 'an University of Architecture and Technoloy, 2013.

[5] Fan Xiaofang. The Study of Environment Design of Building Space for the Apartments for the Aged in the City[D]. Chang'an University, 2013.

[6] Wu Dan. Research on the Design of the Apartments for the Aged Based on Market Operation Mode [D]. Hunan University, 2013.

[7] Mei Junyan. Research on the Design of Environment Demand for the Apartments for the Aged with the Perspective of Environmental Ethics[D]. Central South University, 2012.

Li Zhihan. The Study of landscape design with rehabilitation for the Apartments for the Aged[D]. Chang'an University, 2013. 